\title{
Simulation of Net Meter Connected to Microgrid
}

\author{
Vinayaka R Deskar ${ }^{1}$, Prof. Pradeep Kumar ${ }^{2}$ \\ PG Scholar, Department of EEE, NMAMIT, Nitte, Karkala, Udupi, India ${ }^{1}$ \\ Assistant Professor, Department of EEE, NMAMIT, Nitte, Karkala, Udupi, India ${ }^{2}$
}

\begin{abstract}
In India, as there is great demand for solar energy, it is must for us to switch towards that natural energy to avoid the energy crisis. In India already the implementation of solar metering is started which has two categories, one is Gross Metering and other is Net Metering This paper includes simulation of a Net Meter to which an owner and some customers are connected through Micro-Grid, to avail the benefit. This paper also includes the Micro-grid in such a way that, it is not connected to the Macro-Grid, instead it is only meant for the owner and some customers, where we can call it as Private Micro-Grid. Whenever the grid failure happens the extra generated energy will be sent through the Micro-Grid that reaches to the customers. The Net Meter connected to it, will not only calculates the power from and to the Macro-grid, it also computes the power to the Micro-grid and the respective incentives to be paid from and to the electricity board and also the incentives from customers to the owner. This simulation is carried out in MATLAB SIMULINK.
\end{abstract}

Keywords: Net Meter, Microgrid, MPPT, P\&O Method, Macrogrid.

\section{INTRODUCTION}

India is one among the developing countries, where there lot of energy crisis. In India the amount of energy utilized is more than the generation. The only possible way to reduce this crisis and to generate more energy we need to move towards the renewable energy sources. The source of renewable energy is solar energy, which is largely and easily available. So to generate solar energy as more as possible, rooftop solar systems are already implemented where solar metering is used. In solar Metering there are two types, one is Gross Metering where the owner has the provision to feed the energy generated from solar to utility grid completely and the respective incentives are received from the electricity board and another is Net Metering, here the owner has the option to use generated energy or he may send the generated energy to utility grid and the incentives depends upon the usage made by the owner.Here the net meter decides whether the owner has to pay to electricity board or vice versa. In this paper the programming and the simulation of Net Meter using MATLAB Simulink is described. For this simulation Solarex MSX64 a 64W solar panel is used which is connected to the inverter with MPPT controller where the maximum power point is tracked and solar panel is made to work under that point to get maximum power output and the solar DC output is converted to AC. As the Microgrid is a single phase we used a boost converter to increase the voltage level to 230V. Finally MATLAB Function is written to monitor the energy usage and the incentives to be paid, which we call it as Net Meter.

\section{SYSTEM OVERVIEW AND WORKING PRINCIPLE}

The figure 2.1 shows the block diagram of the system which includes

A. PV Panel

B. Inverter and MPPT control

C. Microgrid

D. Net Metering

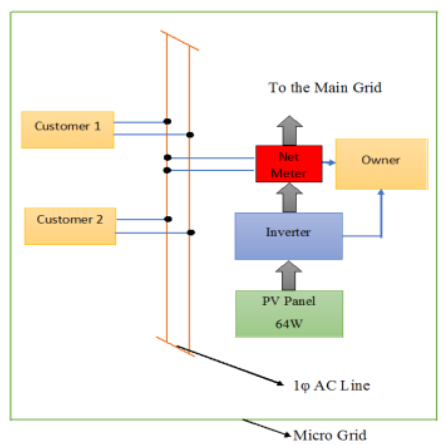

Figure 2.1: System Block Diagram. 


\section{A. PV Panel:}

To generate the solar energy we need solar panels where the solar cells are connected in series and in parallel to increase voltage and current respectively. In this simulation a 64W Solarex MSX64 solar panel is used which has $17.5 \mathrm{~V}$ output voltage and 3.66A of current. This panel outputs the maximum power that is $64 \mathrm{~W}$ at $17.5 \mathrm{~V}$ [1].

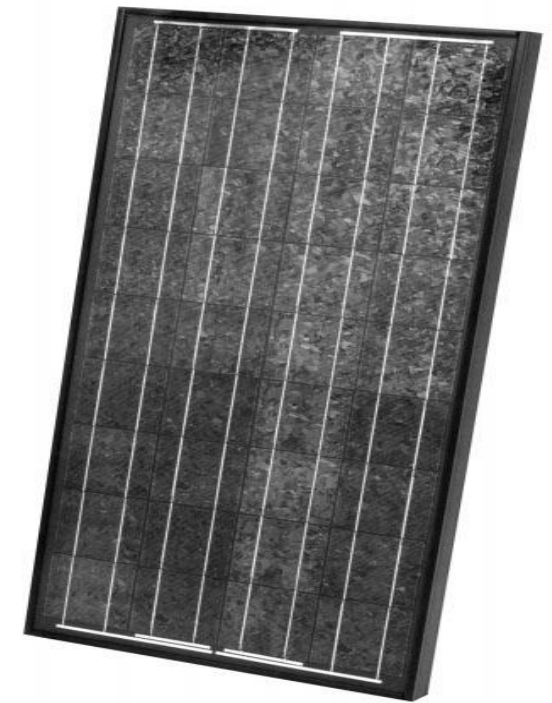

Figure 2.2: Solarex MSX64 Solar Panel.

This solar panel output is connected to inverter with MPPT controller.

B. Inverter and MPPT Controller:

The output voltage from the solar panel is fed to the single phase inverter where the DC voltage get converted to AC. Here MPPT Controller is used to track the maximum power point. For this simple and efficient perturb and observe algorithm is used [3].

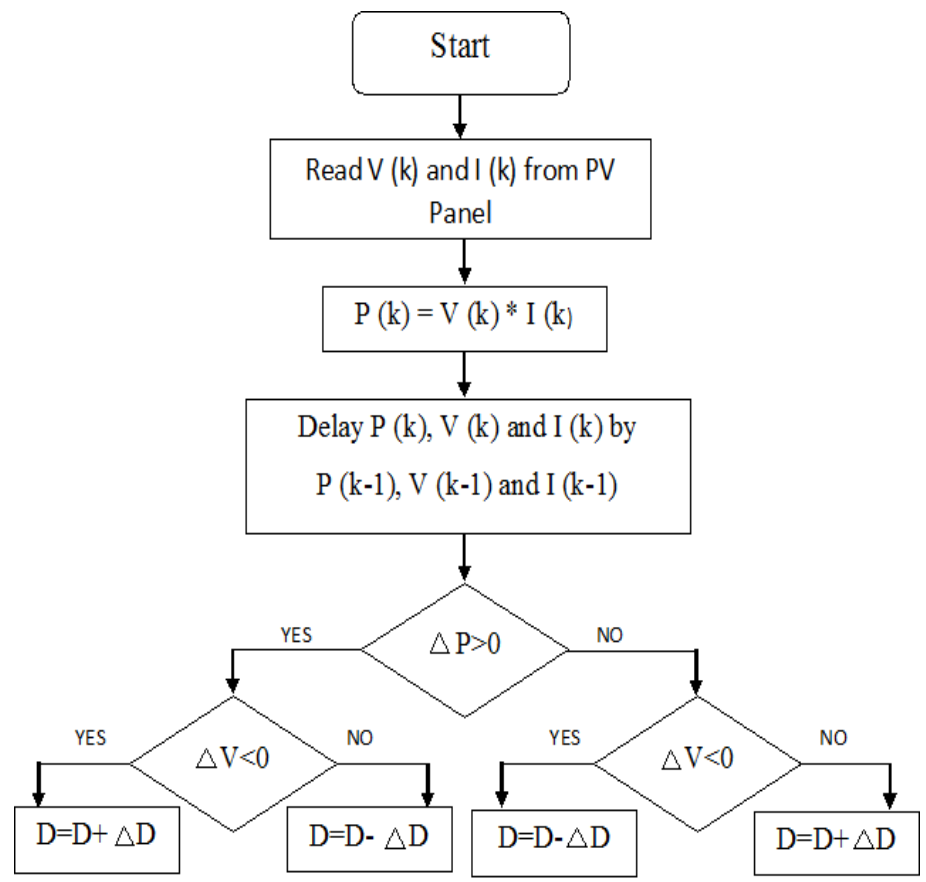

Figure 2.3: Flowchart for MPPT Controller

The figure 2.3 shows the flow graph for MPPT controller using P\&O algorithm. Here the Voltage V (k) and Current I $(\mathrm{K})$ is read from the solar panel and then the Power $\mathrm{P}(\mathrm{k})$ is calculated. These $\mathrm{V}(\mathrm{k}), \mathrm{I}(\mathrm{k})$ and $\mathrm{P}(\mathrm{k})$ are delayed by $(\mathrm{k}-1)$ and the change in power $\Delta \mathrm{P}$ is calculated and checked whether it is greater than zero or not. If $\Delta \mathrm{P}$ is greater than zero 
then change in voltage $\Delta \mathrm{V}$ is calculated and if it is less than zero Duty Cycle $\mathrm{D}$ is decremented by $\Delta \mathrm{D}$ if it is greater than zero the $\mathrm{D}$ is incremented by $\Delta \mathrm{D}$. If $\Delta \mathrm{P}$ is less than zero then $\Delta \mathrm{V}$ is calculated and the reverse of above operation is performed. Here to make the solar panel to work in particular voltage the duty cycle is varied according to the changes that happens in the irradiation.

\section{Microgrid:}

It is a localized grid which is made to operate autonomously to increase the strength and to reduce the disturbances. There are mainly five types of Microgrid [2][4],

1. Single Customer Microgrid:

Only one user is connected to this type of Microgrid.

2. Partial Feeder Microgrid:

Here there is only one Generator and many users are connected.

3. Full Feeder Microgrid:

This is the combination of above two Microgrids.

4. $\quad$ Full Substation Microgrid:

It is the combination of all the above Microgrids.

5. Off Grid Microgrid:

This type of Microgrid is not connected to any Macrogrid that is utility grid. It is independent of main grid. This type of Microgrid is used in Islands. Here there may be single or many generators and many users.

We used Off Grid Microgrid in our Simulation.

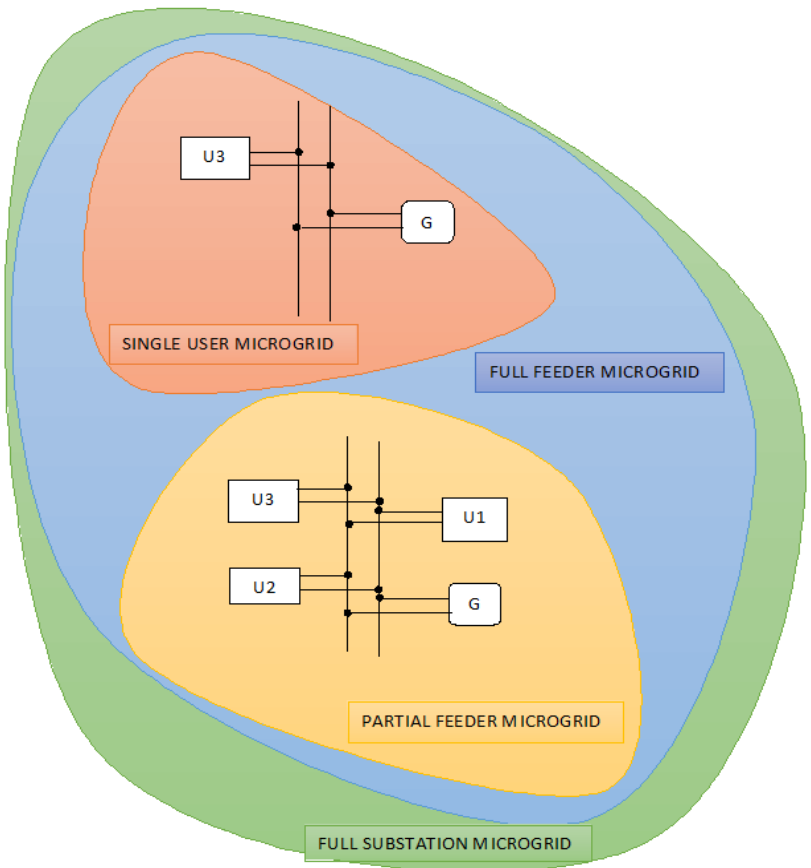

Figure 2.4: Types of Microgrid.

\section{Net Metering:}

Consider, an owner who got his building installed with rooftop PV system with Net Meter. Suppose, the amount of power required for building is less than the solar power generated then he will use the main grid power. If the building requirement is less than the generated power, he has the provision to send that extra power through the Macrogrid. This process we call it as Net Metering. The device used for this calculation is called as Net Meter.

When the owner is using the power from Macrogrid the Net Meter will run in usual direction, if the owner is feeding the extra generated power to the Macrogrid the Net Meter will run in opposite direction, finally that provides the complete information about the incentives that is to be paid by the owner to the electricity board or vice versa depending upon the usage. 
NMAM Institute of Technology, Nitte

Vol. 4, Special Issue 2, April 2016

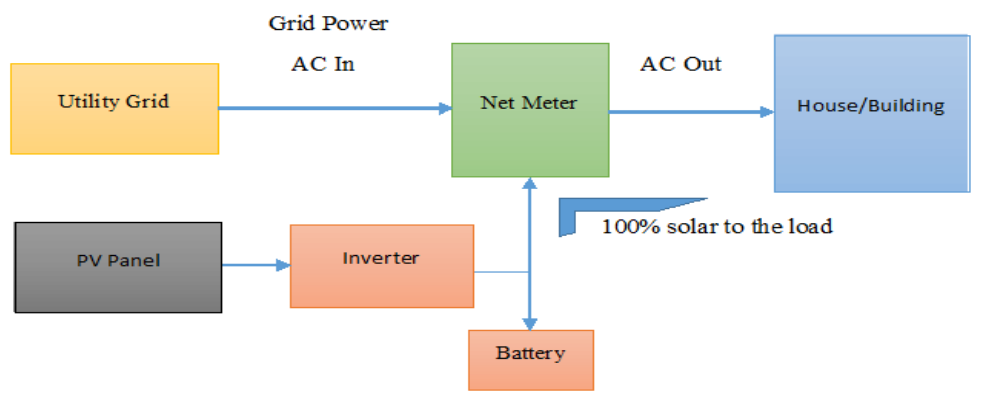

Figure 2.5: Net Meter Connections.

E. Principle of Working:

The principle of working is explained with help of flow chart shown in the figure 2.6. When the system starts it checks whether the power generated from solar panel is excess, if it is excess it proceeds further to feed that power to the Macrogrid. If it is not excess, that means the owner has utilized all the power generated from solar panel. Then it checks whether the Macrogrid is available to feed the power, if it is then the power will be fed to the Macrogrid by matching many parameters such as frequency, phase grid and many. If the Macrogrid is not available it then checks whether the customers in the Microgrid need any power. If they are in need of power then the power is sent through the Microgrid and their usage is monitored in the Net Meter. Finally if neither the Microgrid nor the Macrogrid is available at that time, the extra power that is generated is stored in some sort of efficient battery like flow battery and many.

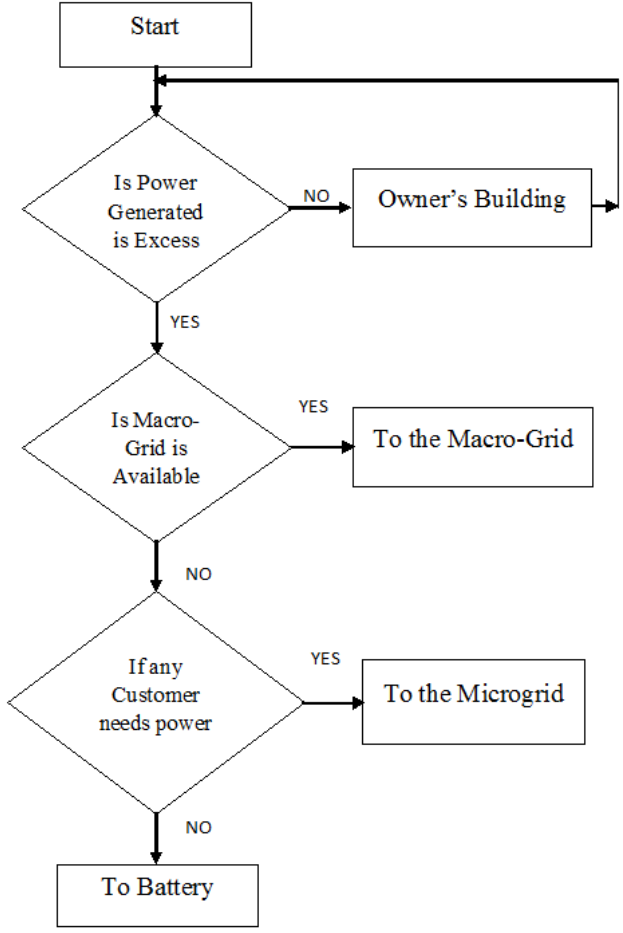

Figure 2.6: System Working Flow Chart

\section{NET METER AND ITS SIMULATION RESULTS}

The input to the Net meter is the Current and the Voltage from the Microgrid and Macrogrid. The output of the solar is boosted to $230 \mathrm{~V}$ and converted to AC so that it can fed to the Single Phase Microgrid. The modelling of solar panel in MATLAB Simulink is carried out using some standard equations for load current $\mathrm{I}_{\mathrm{L}}$, Diode Current $\mathrm{I}_{\mathrm{D}}$, and many other and is shown in the figure 3.1.The boost converter is shown in the figure 3.4. MPPT using Perturb and observe algorithm shown in figure 3.5 will make the solar panel to work in particular voltage where it can deliver the maximum power output. It is not so easy to feed the power to the Macrogrid, where it has to be converted to the three phase and the synchronization is must between the inverter and the grid where the parameters such as the phase, frequency, voltage and many come to account. As the Microgrid is the Off - Grid Microgrid the synchronization is to be achieved between the grid and the load. 
Vol. 4, Special Issue 2, April 2016

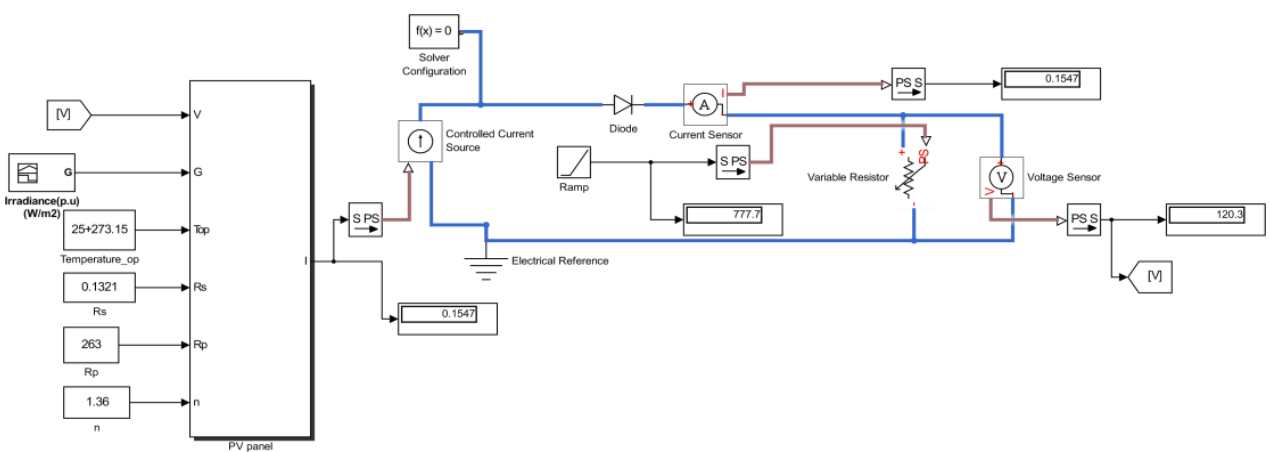

Figure 3.1: Solarex MSX 64 Simulink Model.

The IV and PV plot of the solar panel is shown below figure 3.2 and 3.3 respectively. Where the maximum power is available at $17 \mathrm{~V}$ and $3.82 \mathrm{~A}$ current.

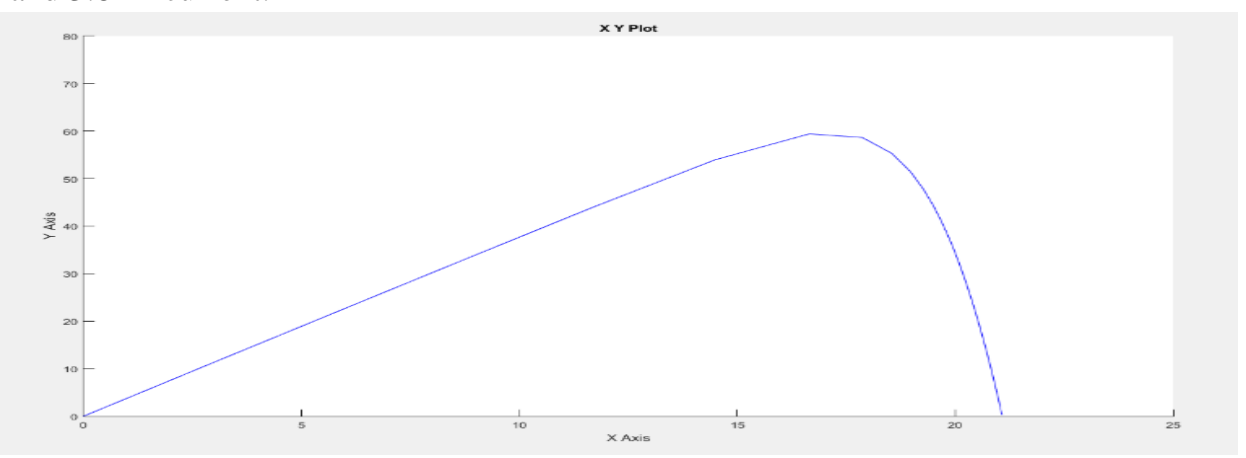

Figure 3.2: PV Plot for Solarex MSX64.

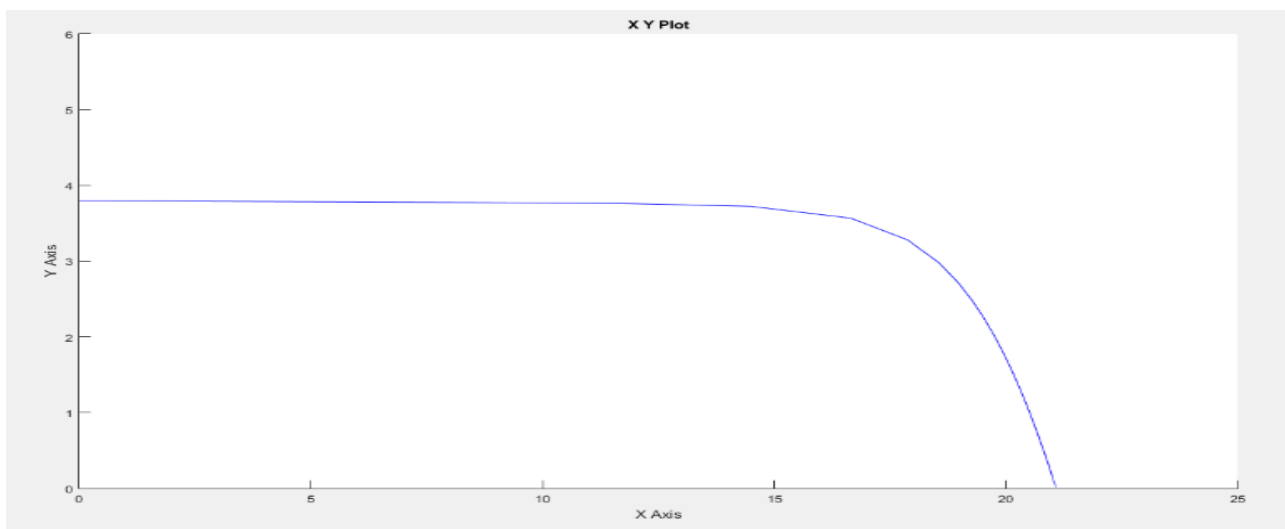

Figure 3.3: IV Plot for Solarex MSX64.

So from the graph of PV it is came to know that the panel outputs maximum power at $17 \mathrm{~V}$ and for this the MPPT controller is used that make the panel to function at $17 \mathrm{~V}$ constantly irrespective of the solar irradiation. By placing these solar panels in series the output voltage is converted to $230 \mathrm{~V}$ DC using boost converter.

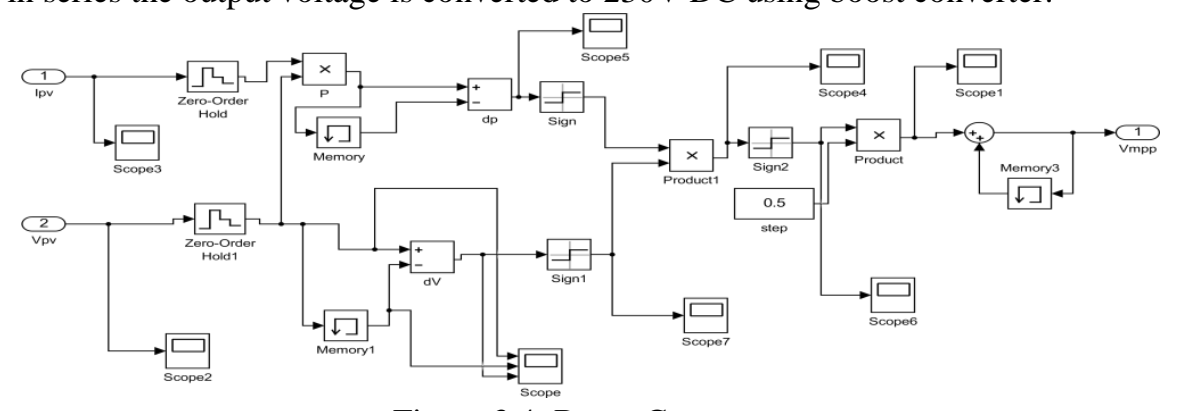

Figure 3.4: Boost Converter 
Vol. 4, Special Issue 2, April 2016

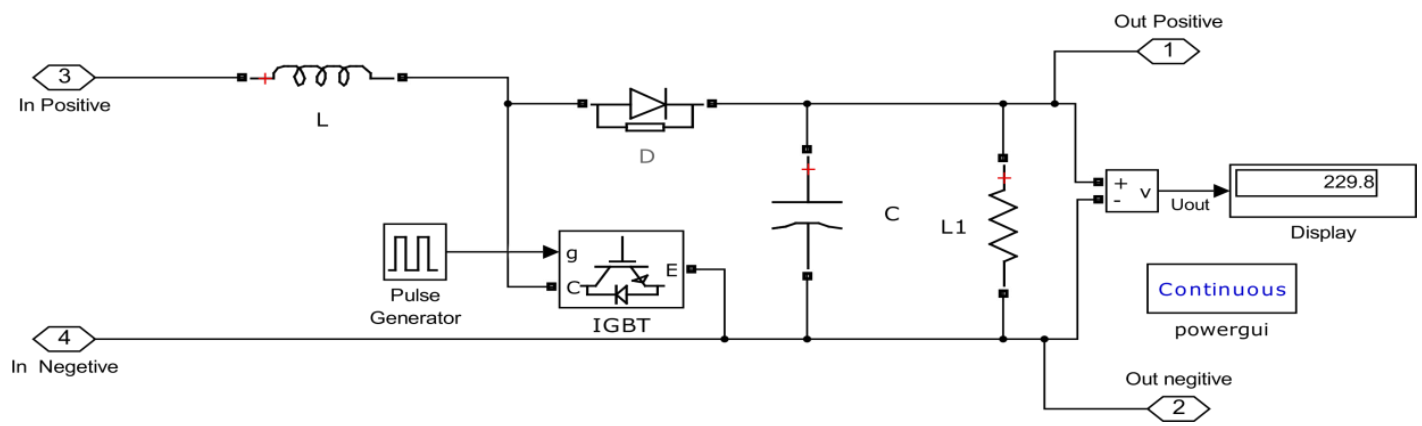

Figure 3.5: MPPT using P\&O Algorithm

In Net Meter the following calculation will be carried out.

$\mathrm{t}=$ Simulation Time.

time $=$ Simulation Time In hour.

$\mathrm{C} 1$ = Control Signal 1. When $\mathrm{C} 1=1$, Net meter will calculate the power from the grid to the owner. Then,

Power=V1*I1.

Total Power=Power*(1000/Power)*time.

Power in Units=Total Power $/ 1000$.

Amount $1=$ Power in Units*2.5.

Amount = Amount1-Amount2.

The MATLAB Simulink function is shown in the figure 3.6. Where,

$\mathrm{V} 1=$ Voltage in the grid when the owner is using the power from the Macrogrid.

I1 = Current in the grid when the owner is using the power from the Macrogrid.

V2 = Voltage in the grid when extra energy is fed to the Macrogrid.

$\mathrm{I} 2$ = Current in the grid when the extra energy is fed to the Macrogrid.

V3 = Voltage in the Microgrid

I3 = Current in the Microgrid.

Amount $1=$ The amount that is to be paid by the owner to the electricity board.

Amount 2 = The incentives that is to be paid by the electricity board to the owner.

Amount $3=$ The incentive that is to be paid by the customer connected to the Microgrid.

Amount $=$ Total amount.

If it is negative then electricity board has to pay to the owner or else vice versa.C1, C2, C3 are the control signals used to control the energy flow from and to the grid. To measure the simulation time a digital clock is used that takes the value of the total simulation time.

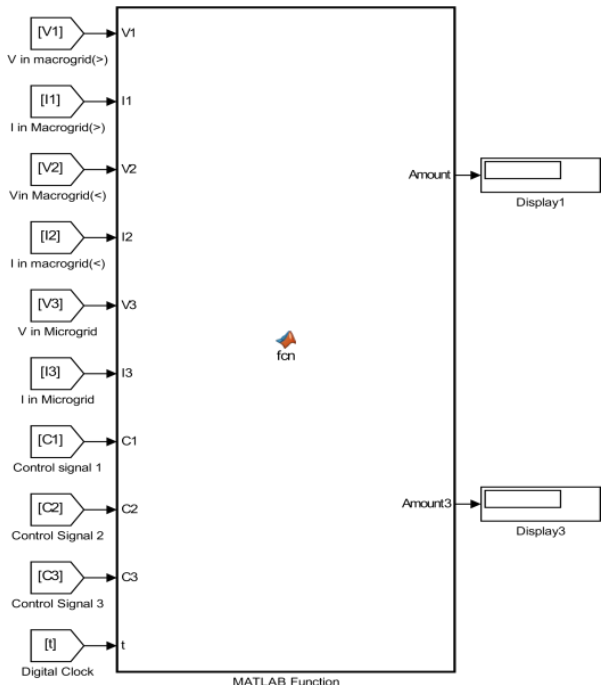

Figure 3.6: Net Meter Function in MATLAB Simulink. 
Vol. 4, Special Issue 2, April 2016

\section{CONCLUSION}

As there is a need for Electricity, the government has instructed to have the solar rooftop system with the Net Meter is all the buildings. In this concern this paper explained the programming of Net Meter using MATLAB and its connection to the PV system with MPPT controller using perturb and Observe Algorithm where the complete generated power could be used so that the power can be controlled. This programming can used to design the Net Meter using dsPIC controller so that Net Meter can be brought out as a product.

\section{ACKNOWLEDGEMENT}

It is my privilege to express my gratitude to our Head of the Department Dr. Nagesh Prabhu, My guide Mr. Pradeep Kumar, Asst. Prof., for their useful guidance in preparing this paper. I would also like to thank my lecturers and my friends who helped me in writing this paper.

\section{REFERENCES}

[1]. Chandani Sharma, Solar Panel Mathematical Modelling Using Simulink Int.Journal of Engineering Research and Applications www.ijera.com ISSN: 2248-9622, Vol. 4, Issue 5(Version 4), May 2014, pp.67-72.

[2]. Mohammed A. Elgendy, Bashar Zahawi, Assessment of Perturb and ObserveMPPT/Algorithm Implementation Techniques for PV Pumping Applications, Transactions on Sustainable Energy, Vol. 3, No. 1, January2012.

[3]. SajibChakraborty, M. A. Razzak,Md. Sarwar Uddin Chowdhury, SudiptaDey,Design of a Transformer-less Grid Connected Hybrid Photovoltaic and Wind Energy System, The 9th International Forum on Strategic Technology (IFOST), October 21-23, 2014, Coxs Bazar, Bangladesh.

[4]. Microgrid Systems in India is available at http://www.tatapowersolar.com/Solar-Microgrid. 